\title{
Polymorphisms in the mannose binding lectin gene affect the cystic fibrosis pulmonary phenotype
}

\author{
J Yarden, D Radojkovic, K De Boeck, M Macek Jr, D Zemkova, V Vavrova, R Vlietinck, \\ J-J Cassiman, H Cuppens
}

C ystic fibrosis is a common lethal autosomal recessive disease affecting whites with an incidence of about 1 in 2500. The median lifespan is approximately 30 years. Chronic obstruction and infection of the respiratory tract, pancreatic insufficiency, elevated sweat electrolyte concentration, and male infertility characterise this disease. Clinical manifestations are attributed to mutations in the cystic fibrosis transmembrane conductance regulator (CFTR) gene, ${ }^{1}$ which encodes an epithelial chloride channel. ${ }^{2}$ Certain phenotypes of cystic fibrosis, such as pancreatic insufficiency, are highly associated with the CFTR genotype. Pulmonary symptoms are highly variable, even among patients from the same family. ${ }^{3}$ Other genetic factors, as well as environmental factors, thus affect the cystic fibrosis disease phenotype.

In association studies, evidence has been found that mannose binding lectin (MBL) protein affects cystic fibrosis disease. ${ }^{45}$ MBL protein is an important mediator component of the innate immune defense system, which functions as an opsonin and complement activator. It is part of a family of proteins called collectins, because they contain collagen-like regions and lectin domains. Through the lectin domain, they bind to carbohydrate structures presented by a wide range of pathogenic bacteria, viruses, fungi, and parasites. Mannose binding lectin protein is synthesised in the liver by hepatocytes and secreted in the blood, and circulates as dimers or hexamers composed of subunits containing three identical polypeptides. ${ }^{67}$

The MBL2 gene is located on chromosome 10q11.2-q21. Three single polymorphic MBL2 alleles are known, which are either caused by a nucleotide substitution in codon 52 (arginine with cysteine, allele $D$ ), codon 54 (glycine with aspartic acid, allele $B$ ) or codon 57 (glycine with glutamic acid, allele $C) .^{8-10}$ These amino acid changes are thought to affect the tertiary structure of the MBL protein collagenous region. Heterozygosity or homozygosity for these mutations results in little or no functional MBL protein, and hence these alleles have been named $O$ (null) alleles. ${ }^{8-11}$ Therefore, the common designation for the presence of any of the mutant null alleles is $O$ whereas the normal allele has been named $A .{ }^{4}$ Several polymorphisms in the promoter region of MBL2 gene also affect MBL protein serum levels. In particular, the $Y / X$ promoter polymorphism affects serum levels of the MBL protein. The $Y$ allele is associated with higher plasma levels of MBL protein; the $X$ allele is associated with lower MBL protein plasma levels. ${ }^{4}{ }^{11}$

MBL2 low producer genotypes (when homozygous or heterozygous for the MBL2 $O$ allele) have been associated with poor prognosis and early death in patients with cystic fibrosis. ${ }^{4}$ However, a modulating role of a genetic factor with disease, based on association studies, should only be treated as tentative until the finding of an association has been replicated in other studies. We therefore investigated whether MBL2 structural variants are associated with pulmonary function or susceptibility to Pseudomonas aeruginosa

\section{Key points}

- Mannose binding lectin (MBL2) has been proposed to modulate disease severity in cystic fibrosis; however association studies should be treated as tentative until such an association has been replicated in other studies. We therefore investigated whether MBL2 gene variants are associated with pulmonary function or susceptibility to Pseudomonas aeruginosa infection in Belgian and Czech patients with cystic fibrosis.

- MBL2 promoter and structural variants were typed by single base primer extension assays in 112 patients with cystic fibrosis and 187 healthy controls. Spirometric data and first age of infection with Pseudomonas aeruginosa were collected retrospectively from patients' medical records, to see if they are associated with cystic fibrosis lung disease severity.

- An association was found for the MBL2 structural variants and severity of cystic fibrosis lung disease. Patients having the MBL2 AO or OO genotypes were more likely to have a more severe pulmonary phenotype than patients having the $A A$ genotype $(p=0.002)$. No association was found between the $M B L 2$ genotype and the first age of infection with $P$. aeruginosa.

- This study confirms an association between MBL2 variants and the cystic fibrosis pulmonary phenotype, and therefore it is very likely that mannose binding lectin protein is indeed a modulating factor in cystic fibrosis disease.

infection in different ethnic groups of cystic fibrosis patients.

\section{METHODS}

\section{Patients and control subjects}

Only cystic fibrosis patients homozygous for the F508del CFTR mutation were included in the study. We recruited 57 patients with cystic fibrosis from the Belgium University Hospital Gasthuisberg and 122 patients with cystic fibrosis from the Czech Republic Cystic Fibrosis Centre at Prague University Hospital Motol. The control population comprised 85 healthy Belgian adult blood donors, 54 healthy Czech adult blood donors and 48 newborns from the Czech Republic. Controls were ethnically matched to patients. For

Abbreviations: CFTR, cystic fibrosis transmembrane conductance regulator; MBL, MBL2, mannose binding lectin; SNP, single nucleotide polymorphism 
Table 1 Primers for PCR amplification of MBL2 fragments

\begin{tabular}{|c|c|c|c|c|c|}
\hline Primer* & $\begin{array}{l}\text { Accession } \\
\text { number }\end{array}$ & Nucleotide sequence $\left(5^{\prime} \rightarrow 3^{\prime}\right)$ & $\begin{array}{l}\text { Primer } \\
\text { concentration }\end{array}$ & $\begin{array}{l}\text { Annealing } \\
\text { temperature }\end{array}$ & PCR product length \\
\hline 47.5 & AF080508 & CAACGTAGTAAGAAATTTCCAGAG & $0.4 \mu \mathrm{M}$ & $57^{\circ} \mathrm{C}$ & $913 \mathrm{bp}$ \\
\hline 959.3 & AF080508 & CCAGGCAGTITCCTCTGGAAGG & $0.4 \mu \mathrm{M}$ & & \\
\hline 621.5 & AF080508 & ACCCAGATTGTAGGACAGAG & $0.1 \mu M$ & $55^{\circ} \mathrm{C}$ & $339 \mathrm{bp}$ \\
\hline 959.3 & AF080508 & CCAGGCAGTTCCTCTGGAAGG & $0.1 \mu \mathrm{M}$ & & \\
\hline
\end{tabular}

*The number preceding the decimal point refers to the nucleotide position of the Genbank DNA sequence of the specified accession number given in the neighbouring column, which also corresponds to the $5^{\prime}$ nucleotide of the oligonucleotide. The annotations .5 and .3 refer to forward and reverse primers, respectively.

the association study of MBL2 with the disease phenotype, only patients between the ages of 12 and 15 years (mean age 13.4 years) were included (40 Belgian and 72 Czech patients); $48 \%$ were male and $52 \%$ were female. All clinical data on patients were retrieved from patients' case records. FEV $\%$ predicted values were calculated according to Knudson et al. ${ }^{12}$ Statistical analysis of lung function was performed on the last $\mathrm{FEV}_{1} \%$ predicted value between the ages of 12 and 15 years. Ages of first infection with $P$. aeruginosa were obtained from the total patient group, which were available from the case records of 116 patients with cystic fibrosis. Patients are followed at the outpatient clinic three monthly. At every visit a sputum sample (or throat swab in patients who do not expectorate) is taken. The age at which $P$. aeruginosa is isolated for the first time is referred to as first infection with $P$. aeruginosa. Association studies involving human subjects have been approved by the ethical committees of both universities.

\section{PCR and single nucleotide extension assay}

We developed multiplex PCR and multiplex single nucleotide primer extension assays, in which single nucleotide polymorphisms (SNPs) of MBL2 were included. The primers used for amplification of the genomic regions covering the SNPs in MBL2, and the single nucleotide primer extension oligonucleotides for the SNPs in these regions are given in tables 1 and 2, respectively.

PCR reactions were performed in a volume of $50 \mu \mathrm{l}$ containing $1 \times$ Gold Buffer (Applied Biosystems), $0.2 \mathrm{mM}$ dNTPs, $2 \mathrm{mM} \mathrm{MgCl}_{2}, 2.5 \mathrm{U}$ AmpliTaq Gold (Applied Biosystems) and 0.5-1.0 $\mu \mathrm{g}$ DNA. The mixture was then incubated in a thermal cycler (PCR System 9700 Applied Biosystems) using the following amplification profile: denaturation at $95^{\circ} \mathrm{C}$ for $5 \mathrm{~min}, 40$ cycles at $95^{\circ} \mathrm{C}$ for $40 \mathrm{~s}, 55^{\circ} \mathrm{C}-$ $57^{\circ} \mathrm{C}$ for 40 seconds and $72^{\circ} \mathrm{C}$ for $2 \mathrm{~min}$, and a final extension step for $10 \mathrm{~min}$ at $72^{\circ} \mathrm{C}$. PCR products were verified by electrophoresis on $2 \%$ agarose gels.

For the single nucleotide primer extension assays, the SNP detection kit (SNaPshot ${ }^{\mathrm{TM}}$, Applied Biosystems) was used. This assay is based on a dideoxy nucleotide triphosphate (ddNTP) single base extension of an unlabelled oligonucleotide primer, which ends $5^{\prime}$ to the SNP that will be typed. By using varying lengths of primers that detect each of the SNPs, different SNPs can be typed in a multiplex reaction. In a first step, free primers and dNTPs of the PCR mixture were removed, by incubating $7.5 \mu \mathrm{l}$ of the PCR reaction with $2.5 \mathrm{U}$ shrimp alkaline phosphatase (SAP) (Amersham Biosciences) and $2 \mathrm{U}$ of Exonuclease I (ExoI) (Amersham Biosciences) at $37^{\circ} \mathrm{C}$ for 1 hour. The enzymes were then inactivated at $75^{\circ} \mathrm{C}$ for $15 \mathrm{~min}$. The extension reaction was prepared with $5 \mu \mathrm{l}$ SNaPshot Multiplex Ready Reaction Mix, $2.3 \mu \mathrm{l}$ of SAP/ExoI treated PCR products, and $0.2-1.25 \mu \mathrm{M}$ of each unlabelled primer. The extension was performed in a thermal cycler (PCR System 9700, Applied Biosystems), using the following temperature profile: denaturation at $96^{\circ} \mathrm{C}$ for $10 \mathrm{~s}$, annealing at $50^{\circ} \mathrm{C}$ for $5 \mathrm{~s}$, and extension at $60^{\circ} \mathrm{C}$ for $30 \mathrm{~s}$, for a total of 25 cycles. Unincorporated ddNTPs were then removed with $1 \mathrm{U}$ of SAP for 1 hour at $37^{\circ} \mathrm{C}$. The enzyme was finally inactivated at $75^{\circ} \mathrm{C}$ for $15 \mathrm{~min}$. Then, $0.5 \mu \mathrm{l}$ of the SNaPshot

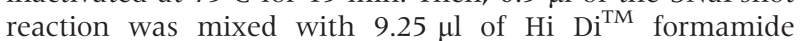
(Applied Biosystems) and $0.25 \mu \mathrm{l} \mathrm{GeneScan}{ }^{\mathrm{TM}} 120 \mathrm{Liz}^{\mathrm{TM}}$ size standard (Applied Biosystems). After denaturation at $95^{\circ} \mathrm{C}$ for $5 \mathrm{~min}$, the mixture was resolved on an ABI PRISM ${ }^{\circledR} 3100$ genetic analyser (Applied Biosystems) and analysed with GeneScan ${ }^{\circledR}$ analysis software (Applied Biosystems).

\section{Statistical analysis}

Database management and statistical analysis was performed with the SAS statistical package, release 8.01 (SAS Institute Inc. Cary, NC, USA), and the SYSTAT package, release 7.0 (SPSS Inc. Chicago, IL, USA). Statistical tests were considered significant when their type I error was less than 0.05 . Differences among the means of $\mathrm{FEV}_{1} \%$ predicted values of Czech and Belgian populations were assessed using a two sample Student's $t$ test after checking whether the variances of the populations were equal or not (using an F test) and adjusting the formula of the Student's $t$ test for this. Comparison between one independent and one dependent qualitative variable were assessed using the $\chi^{2}$ likelihood ratio test (for example, the distribution of patients having an $\mathrm{FEV}_{1} \%$ predicted above or below $70 \%$ as a dependent of the different genotypes), or by the Fisher exact probability test when more than $20 \%$ of the cells had an expected count of less than 5 . When the independent variables were qualitative and the dependent variable was quantitative, a parametric analysis of variance (ANOVA) was done (for example, the

Table 2 Single nucleotide extension primers for MBL2 SNPs

\begin{tabular}{|c|c|c|}
\hline SNP* & $\begin{array}{l}\text { Accession } \\
\text { number }\end{array}$ & Nucleotide sequence $\left(5^{\prime} \rightarrow 3^{\prime}\right)^{\dagger}$ \\
\hline$Y / X(425 \mathrm{~g} / \mathrm{c})$ & AF080508 & AAAAAAAAAAAAAAAAAAAAAACAATGCACGGTCCCATTGTTCTCACTGCCAC \\
\hline$A / D(868 \mathrm{c} / \mathrm{t})$ & AF080508 & GCATCAACGGCTTCCCAGGCAAAGATGGG \\
\hline$A / B(875 \mathrm{~g} / \mathrm{a})$ & AF080508 & CGGCTTCCCAGGCAAAGATGGGCGTGATG \\
\hline$A / C(884 \mathrm{~g} / \mathrm{a})$ & AF080508 & AAAAAAAAAAAAAAAACCTGGTTCCCCCTTTाTT ${ }^{\ddagger}$ \\
\hline
\end{tabular}

*The names of the alleles found at each polymorphic locus are given. The nucleotides for each allele are given in brackets; here the number refers to the polymorphic nucleotide position of the Genbank DNA sequence of the specified accession number given in the neighbouring column.

The length of the oligonucleotide might be increased by the addition of an A-tail.

${ }^{\ddagger} A$ reverse oligonucleotide is used. 
distribution of mean $\mathrm{FEV}_{1} \%$ predicted values as a dependent of genotypes). The Pearson's correlation coefficient was calculated to test the goodness of fit of one independent quantitative value and one dependent quantitative value in a linear regression model (for example, the dependent value of $\mathrm{FEV}_{1} \%$ predicted against the independent value of age).

\section{RESULTS}

The structural and promoter polymorphisms in the MBL2 gene $(A / O, Y / X$ respectively) were typed in 179 cystic fibrosis patients and 187 controls. Hardy Weinberg equilibrium of the different SNPs was checked in the total Belgian patient, Belgian control, Czech patient, and Czech control groups. No Hardy-Weinberg disequilibrium was detected for any group of individuals. We tested for the possibility of population stratification because of differences in ethnicity, age, and sex. The allele or genotype frequencies of Belgian controls with respect to Belgian patients, of Czech controls with respect to Czech patients, of the Belgian control with respect to Czech control population, and of the Belgian patients with respect to Czech patients were not significantly different (table 3); the spirometric variables were distributed equally between Belgian and Czech patients with cystic fibrosis (respectively $68.3 \%$ and $68.8 \% ; p=0.92$ ); and the means of the spirometric values for each genotype did not differ significantly between the Belgian and Czech cystic fibrosis cohorts of age selected patients; therefore the data from the two populations were merged. $\mathrm{FEV}_{1} \%$ predicted values of patients with cystic fibrosis decline with age, ${ }^{13}$ and girls have a steeper decline in pulmonary function than boys. ${ }^{14} \mathrm{FEV}_{1} \%$ predicted values were calculated according to Knudson, which takes into consideration age, sex, and height. ${ }^{12}$ Nevertheless, we tested if the corrected $\mathrm{FEV}_{1} \%$ predicted values were truly independent of sex or age in the present age selected cohort of patients, by comparing the means of the $\mathrm{FEV}_{1} \%$ values between male and female patients, and calculating the Pearson's correlation coefficient for age versus $\mathrm{FEV}_{1} \%$ predicted values. No influence of age $\left(r^{2}=0.005\right)$ or sex $(\mathrm{p}=0.14$, mean difference $=6.4,95 \%$ confidence inter$\mathrm{val}=-14.8$ to 2.0 , two sample student's $t$ test) on the $\mathrm{FEV}_{1} \%$ values was found in the present age selected cohort of patients with cystic fibrosis.

We then tested if the values of $\mathrm{FEV}_{1} \%$ predicted of the cystic fibrosis patients were dependent on MBL2 genotypes (table 4). Given the fact that almost no functional MBL protein is found in individuals homozygous for the $O$ allele, and very low MBL protein levels are found in individuals heterozygous for the $O$ allele, a dominant model for the $O$ allele was tested. At the mean age of our cohort of studied patients with cystic fibrosis (13.4 years), the average $\mathrm{FEV}_{1} \%$ in cystic fibrosis patients is approximately $70 \%$. The group of patients having an $\mathrm{FEV}_{1} \%$ less than $70 \%$ was therefore compared with that having an $\mathrm{FEV}_{1} \%$ higher than $70 \%$. The distribution of MBL2 $A / O$ variants was however not significantly different in patients having an $\mathrm{FEV}_{1} \%$ predicted to be either higher or lower than $70 \%$. The mean $\mathrm{FEV}_{1} \%$ predicted values did not differ significantly between the $A A$ and combined $A O+O O$ genotypes $(\mathrm{p}=0.10)$, but a trend was observed in the relative reduction of lung function. Patients having the $A O$ or $O O$ genotype tended to have worse $\mathrm{FEV}_{1} \%$ predicted values than patients having the $A A$ genotype. In association studies, severely affected patients are compared with mild patients. The discrimination between these two groups of patients to be used in association studies is, however, not straightforward. Only SNPs with a large contribution in modulation are very likely to be detected in association studies when the most severely affected patients are compared with the milder ones. Most probably however, cystic fibrosis lung disease is affected by a large number of modulating genes, each of them expected to have a modest contribution. In the latter case an association might not be detected when only the most severe patients are studied, since each SNP might not be present in all severely affected patients (false negatives in the severest group of patients), while it might be still present in milder patients (false positives in the milder group of patients). Moreover, a modulating role of an SNP might only become penetrant at higher ages. This is even more relevant given the increasing lifespan of cystic fibrosis patients. Therefore, when studying paediatric patients, no effect or only a modest effect might be seen, resulting in cystic fibrosis disease that is not yet classified as moderate or severe. However, an association might still be detected if the mildly affected patients are compared with both the severe and moderately affected patients, rather than the severely affected patients alone. A cutoff of $90 \% \mathrm{FEV}_{1}$ predicted value was therefore also used to discriminate between very mildly affected patients and all other patients with cystic fibrosis. When $90 \% \mathrm{FEV}_{1}$ predicted value was used for discrimination in lung disease severity, a significantly higher proportion of patients having an $\mathrm{FEV}_{1}$ predicted value higher than $90 \%$ were homozygous for the $A A$ genotype compared with patients having an $\mathrm{FEV}_{1}$ predicted value lower then $90 \%(p=0.002)$. Specifically, the three AO patients having an $\mathrm{FEV}_{1}$ higher than $90 \%$ carried the $A B$ MBL2 genotype. In the group of patients having an $\mathrm{FEV}_{1}$ lower than $90 \%, 22$ were typed as $A B, 5$ had the $A C$ genotype, 14 patients had the $A D$ genotype, and 1 patient had the $B C$ MBL2 genotype.

A combined test of the MBL2 $A / O$ and MBL2 $Y / X$ polymorphisms was also performed. The MBL2 gene high producers $A A-Y Y$ and $A A-Y X$ were tested against the MBL2 gene low producers found in this study $(A A-X X, A O-X X, A O$ $X Y$, and $O O-Y Y$ ) (table 4). The distribution of the combined genotypes was not significantly different in patients having $>70 \% \mathrm{FEV}_{1}$ predicted compared with patients having $<70 \%$ $\mathrm{FEV}_{1}$ predicted, but was significantly different when $90 \%$ $\mathrm{FEV}_{1}$ predicted was used as a cutoff. A significantly higher proportion of patients having an $\mathrm{FEV}_{1}$ predicted value higher

Table 3 Allele and genotype frequencies of MBL2 gene variants in patients with cystic fibrosis and control subjects

\begin{tabular}{|c|c|c|c|c|c|c|c|c|c|c|}
\hline & \multicolumn{5}{|l|}{ MBL2 A/O } & \multicolumn{5}{|l|}{ MBL2 $Y / X$} \\
\hline & $\overline{A A}$ & $A O$ & 00 & $A$ & 0 & $\overline{Y Y}$ & $Y X$ & $x x$ & $Y$ & $x$ \\
\hline Czech patients $n=122$ & $72(59.0)$ & $47(38.5)$ & $3(2.5)$ & $191(78.3)$ & $53(21.7)$ & $64(52.9)$ & $51(42.1)$ & $6(5.0)$ & $179(74.0)$ & $63(26.0)$ \\
\hline xtients $n=57$ & $32(56.1)$ & $24(42.1)$ & 11181 & 88 (77.2) & $26(22.8)$ & 36 (63.2) & $16(28.1)$ & $5(8.8)$ & 88 (77.2) & $26(22.8)$ \\
\hline Total patients $n=179$ & $104(58.1)$ & 71 (39.7) & $4(2.2)$ & $279(77.9)$ & $79(22.1)$ & $99(57.6)$ & $63(36.6)$ & $10(5.8)$ & $261(75.9)$ & $83(24.1)$ \\
\hline Czech controls $n=102$ & $62(63.9)$ & $31(32.0)$ & $4(4.1)$ & $155(79.9)$ & $39(20.1)$ & $53(52.0)$ & $43(42.2)$ & $6(5.9)$ & $149(73.0)$ & $55(27.0)$ \\
\hline Belgium controls $n=85$ & $45(52.9)$ & $32(37.6)$ & $8(9.4)$ & $122(71.8)$ & $48(28.2)$ & $54(63.5)$ & $28(32.9)$ & $3(3.5)$ & $136(80.0)$ & $34(20.0)$ \\
\hline Total controls $n=187$ & $107(58.8)$ & $63(34.6)$ & $12(6.6)$ & $277(76.1)$ & $87(23.9)$ & $107(57.2)$ & $71(38.0)$ & $9(4.8)$ & $285(76.2)$ & $89(23.8)$ \\
\hline
\end{tabular}

For each allele or genotype, the number of alleles or individuals is given, percentages are given in brackets. The distribution of the genotypes for the patients with cystic fibrosis is given irrespective of age. There may be a difference in number of controls typed for the structural variants and promoter variants due to technical problems. 
Table 4 Distribution of MBL2 genotypes according to $\mathrm{FEV}_{1} \%$ in patients aged 12 to 15 years

\begin{tabular}{|c|c|c|c|c|c|}
\hline \multirow[b]{2}{*}{ Structural variants } & \multicolumn{2}{|l|}{ Genotype } & \multirow[t]{2}{*}{ Mean difference } & \multirow[t]{2}{*}{$95 \%$ confidence interval } & \multirow[t]{2}{*}{$p$ value } \\
\hline & $\overline{A A}$ & $A O+O O$ & & & \\
\hline $\begin{array}{l}\text { Mean } \mathrm{FEV}_{1 \%} \text { predicted (standard } \\
\text { deviation) }\end{array}$ & $71.8(22.5)$ & $64.8(22.1)$ & 7.0 & -1.5 to 15.6 & 0.10 \\
\hline No $>70 \% \mathrm{FEV}_{1}(\%) n=59$ & $37(62.7 \%)$ & $22(37.3 \%)$ & & & 0.51 \\
\hline No $<70 \% \mathrm{FEV}_{1}(\%) \mathrm{n}=53$ & $30(56.6 \%)$ & $23(43.4 \%)$ & & & \\
\hline No $>90 \%$ FEV $1(\%) n=23$ & $20(87.0 \%)$ & $3(13.0 \%)$ & & & 0.002 \\
\hline No $<90 \% \mathrm{FEV}_{1}(\%) n=89$ & $47(52.8 \%)$ & $42(47.2 \%)$ & & & \\
\hline Structural or promoter variants & High* & $\operatorname{Low}^{\dagger}$ & & & \\
\hline $\begin{array}{l}\text { Mean } \mathrm{FEV}_{1 \%} \text { predicted (standard } \\
\text { deviation) }\end{array}$ & $72.2(22.9)$ & $65.3(22.7)$ & 6.9 & -1.4 to 15.3 & 0.10 \\
\hline No $>70 \% \mathrm{FEV}_{1}(\%) n=59$ & $34(57.6 \%)$ & $25(42.4 \%)$ & & & 0.36 \\
\hline No $<70 \%$ FEV $_{1}(\%) n=53$ & $26(49.1 \%)$ & $27(50.9 \%)$ & & & \\
\hline No $>90 \% \mathrm{FEV}_{1}(\%) \mathrm{n}=\mathbf{2 3}$ & $18(78.3 \%)$ & $5(21.7 \%)$ & & & 0.006 \\
\hline No $<90 \% \mathrm{FEV}_{1}(\%) \mathrm{n}=89$ & $42(47.2 \%)$ & $47(52.8 \%)$ & & & \\
\hline
\end{tabular}

than $90 \%$ had the combined MBL2 high producing genotypes $A A-Y Y$ and $A A-Y X(\mathrm{p}=0.006)$.

For 116 cystic fibrosis patients we had records of the age at the first onset of $P$. aeruginosa colonisation. MBL2 gene structural variants alone, or in combination with MBL2 gene promoter variants, did not significantly associate with the age at the first infection with $P$. aeruginosa $(\mathrm{p}=0.88$ and 0.6 , respectively).

\section{DISCUSSION}

The patients in this study were derived from two white populations within Europe. We decided to group the patients, to strengthen the statistical power of the study. To exclude variables that might affect the phenotype, the following precautions were taken. Only patients homozygous for the F508 deletion were included, to exclude an effect of the CFTR genotype on disease. Patients from only two centres were included, to exclude variability in disease status caused by different treatments and variability in measurement of clinical variables. Only a small age group of patients was studied here. Indeed, the effect of a mutation might become only penetrant by age. Moreover, at any age, a patient might have a mild form of the disease, but it might still become severe when the patient is older. It is indeed important to neutralise the age variable as much as possible, since $\mathrm{FEV}_{1} \%$ predicted values of patients with cystic fibrosis declines more rapidly with age than in the general population, and therefore may interfere with results when testing pulmonary function as a dependent of genotype distribution. The fact that $\mathrm{FEV}_{1} \%$ values did not specifically differ with the age of the patients within the present cohort supports the credibility of the chosen age group. We also checked whether we could compare the disease severity between subjects without the influence of sex, since girls are known to have significantly lower $\mathrm{FEV}_{1} \%$ values than boys. However, we found no significant difference in corrected $\mathrm{FEV}_{1} \%$ values between male and female patients within the present cohort of age selected patients. All genotype distributions of patients and controls were in Hardy-Weinberg equilibrium ruling out population stratification of the patient groups. The frequencies of the tested genotypes and $\mathrm{FEV}_{1} \%$ values were not significantly different between the two populations, allowing us to pool the populations.

We found an altered distribution of the MBL2 gene polymorphisms, depending on pulmonary function. However, when only a limit of $90 \% \mathrm{FEV}_{1}$ predicted value was used, an effect of the MBL2 gene phenotype was observed. Specifically, $A A$ homozygotes were found to associate with a better pulmonary phenotype than $A O$ heterozygotes and $O O$ homozygotes. The $A O$ and $O O$ MBL2 genotypes are known to result in low MBL protein levels. Also, when the $Y / X$ locus was further taken into consideration, high producers $A A-Y Y$ and $A A-Y X$ MBL2 genotypes were found to have better pulmonary function than low producers $A A-X X, A O-X Y, A O-X X$, and $O O-Y Y$ MBL2 genotypes. It cannot be excluded that the observed association might be caused by another polymorphism in the MBL2 gene, or even a linked gene. However, given the well known functional biological consequences of the studied polymorphisms, it is very likely that the studied polymorphisms are directly involved.

The fact that we found no altered distribution of MBL2 gene polymorphisms depending on pulmonary function when $70 \% \mathrm{FEV}_{1}$ predicted value was used as a cutoff for discriminating pulmonary function, and a significant difference was found when the milder $90 \% \mathrm{FEV}_{1}$ predicted value was used instead, confirms our working hypothesis that modulating polymorphisms might not be fully penetrant at a given age. Therefore, at the average age of 13.4 years, MBL2 gene modulation of cystic fibrosis pulmonary disease is observed in severely and moderately affected patients in the present study, rather than in the severely affected patients alone. In a previous study, MBL2 gene polymorphisms seemed to have a stronger effect on pulmonary function, perhaps as a result of the older patient group studied. The range of ages of the previous study was 7-4l years with a median age of 16.2 years ${ }^{4}$ compared with the patients of the present study, of 12-15 years with a median age of 13.3 years. Also, the earlier study had typed four times more patients as being homozygous for the $O$ allele, which may influence results since these patients had an overall lower $\mathrm{FEV}_{1} \%$ value than patients typed as $A O{ }^{4}$ Another small study, that paired 11 cystic fibrosis patients typed as MBL2 $A O$ and $O O$ with 11 age and sex matched cystic fibrosis patients with the MBL2 $A A$ genotype found a weak association of MBL2 gene variants with $\mathrm{FEV}_{1} \%$ predicted. The power of this study is questionable because of the small group of patients studied. ${ }^{5}$

No significant association was found between the age at first infection with $P$. aeruginosa and MBL2 $A / O$ genotypes or combined $A / O$ and $Y / X$ genotypes. P. aeruginosa infection is the most common pulmonary infection in cystic fibrosis patients. ${ }^{15}$ Progression of lung disease unequivocally accelerates after $P$. aeruginosa acquisition, ${ }^{16}$ therefore, the younger the age of first infection with $P$. aeruginosa, the more rapid the decline in pulmonary function. Albeit patients with a very mild pulmonary phenotype associate with MBL2 high producers of protein, MBL protein does not seem to protect 
our patients from $P$. aeruginosa. In a previous study, the differences in lung function between $A A$ MBL2 patients and patients who were either $A O$ or $O O$ was found only in patients who had chronic $P$. aeruginosa infection. ${ }^{4}$ However, in agreement with the present study, they found that MBL protein offered no protection against $P$. aeruginosa with respect to the prevalence of chronic infection or the age at onset of infection. ${ }^{4} \mathrm{MBL}$ is not directly secreted in the lungs, but is secreted into the circulation by the liver. It may well be that the high production of MBL protein protects patients by other means than against $P$. aeruginosa, and in this way the general health of these patients, enabling them to combat the manifestations of cystic fibrosis. Indeed, the presence of cirrhosis in cystic fibrosis patients is significantly associated with $A O$ and $O O$ MBL2 genotypes. ${ }^{17}$ Liver cirrhosis would contribute to the worsening health of cystic fibrosis patients, weakening their general health.

A modulating role of a genetic factor with disease, based on association studies, should only be treated as tentative until the finding of an association has been confirmed in other studies. This study now confirms an association between MBL2 gene variants and the cystic fibrosis pulmonary phenotype, and it is therefore very likely that MBL2 is indeed a modulating factor in cystic fibrosis disease.

\section{Authors' affiliations}

J Yarden, D Radojkovic, R Vlietinck, J-J Cassiman, H Cuppens, Department for Human Genetics, KULeuven, Herestraat 49, O\&N6, 3000 Leuven, Belgium

D Radojkovic, Institute of Molecular Genetics and Genetic Engineering, Vojvode Stepe 444a, Belgrade, Serbia and Montenegro

K De Boeck, Department of Paediatrics, UZ Gasthuisberg, Herestraat 49, 3000 Leuven, Belgium

M Macek Jr, D Zemkova, V Vavrova, Institute of Biology and Medical Genetics and Department of Paediatrics, Charles University Prague and University Hospital Motol, Cystic Fibrosis Centre, V Uvalu 84, CZ 15006 Prague, Czech Republic

These investigations have been supported by the CF-PRONET (QCRT2000-01005) grant from the European Commission, the Interuniversity Poles of Attraction Program (P5/25-H) grant, a grant (GOA 99/07) from the Onderzoeksraad KU Leuven, the Alphonse and Jean FortonKoning Boudewijn Stichting (2000 14 R7115 BO) grant, grant 1417 from the Ministry of Science and Technology of the Republic of Serbia, MZ CR-00000064203,6464-3 and MSMT CR-LN00A079, 111300003. J-J Cassiman is holder of the Arthur Bax and Anna Vanluffelen Chair of Human Genetics.

Conflicts of interest: none declared.
Correspondence to: H Cuppens, Department for Human Genetics, KULeuven, Herestraat 49, O\&N6, 3000 Leuven, Belgium; harry. cuppens@med.kuleuven.ac.be

Revised version received 18 February 2004

Accepted for publication 22 February 2004

\section{REFERENCES}

1 Welsh MJ, Tsui L-C, Boat TF, Beaudet AL. Cystic fibrosis. In: Scriver CR, Beaudet AL, Sly WS, Valle D, eds. The metabolic and molecular basis of inherited disease, 7th ed. New York: McGrawHill, 1995:3799-876.

2 Sheppard DN, Welsh MJ. Structure and function of the CFTR chloride channel. Physiol Rev 1999:79:S23-45.

3 Santis G, Osborne L, Knight RA, Hodson ME. Independent genetic determinants of pancreatic and pulmonary status in cystic fibrosis. Lancet 1990;336:1081-4.

4 Garred P, Pressler T, Madsen HO, Frederiksen B, Svejgaard A, Hoiby N, Schwartz $M$, Koch $C$. Association of mannose-binding lectin gene heterogeneity with severity of lung disease and survival in cystic fibrosis. J Clin Invest 1999;104:431-7.

5 Gabolde M, Guilloud-Bataille M, Feingold J, Besmond C. Association of variant alleles of mannose binding lectin with severity of pulmonary disease in cystic fibrosis: cohort study. BMJ 1999:319:1166-7.

6 Petersen SV, Thiel S, Jensenius JC. The mannan-binding lectin pathway of complement activation: biology and disease association. Mol Immunol 2001;38:133-49.

7 Lu J, Teh C, Kishore U, Reid KB. Collectins and ficolins: sugar pattern recognition molecules of the mammalian innate immune system. Biochim Biophys Acta 2002;1572:387-400

8 Madsen HO, Garred P, Kurtzhals JA, Lamm LU, Ryder LP, Thiel S, Svejgaard A. A new frequent allele is the missing link in the structural polymorphism of the human mannan-binding protein. Immunogenetics 1994;40:37-44.

9 Sumiya M, Super M, Tabona P, Levinsky RJ, Arai T, Turner MW Summerfield JA. Molecular basis of opsonic defect in immunodeficient children. Lancet 1991;337:1569-70.

10 Lipscombe RJ, Sumiya M, Hill AV, Lau YL, Levinsky RJ, Summerfield JA, Turner MW. High frequencies in African and non-African populations of independent mutations in the mannose binding protein gene. Hum Mol Genet 1992;1:709-15.

11 Steffensen R, Thiel S, Varming K, Jersild C, Jensenius JC. Detection of structural gene mutations and promoter polymorphisms in the mannanbinding lectin (MBL) gene by polymerase chain reaction with sequencespecific primers. J Immunol Methods 2000;241:33-42.

12 Knudson RJ, Lebowitz MD, Holberg CJ, Burrows B. Changes in the normal maximal expiratory flow-volume curve with growth and aging. Am Rev Respir Dis 1983;127:725-34.

13 Corey M, Edwards L, Levison $\mathrm{H}$, Knowles $M$. Longitudinal analysis of pulmonary function decline in patients with cystic fibrosis. J Pediatr 1997;131:809-14.

14 Davis PB. The gender gap in cystic fibrosis survival. J Gend Specif Med 1999:2:47-51.

15 Ratien F, Doring G. Cystic fibrosis. Lancet 2003;361:681-9.

16 Kosorok MR, Zeng L, West SE, Rock MJ, Splaingard ML, Laxova A, Green CG, Collins J, Farrell PM. Acceleration of lung disease in children with cystic fibrosis after Pseudomonas aeruginosa acquisition. Pediatr Pulmonol 2001:32:277-87.

17 Gabolde M, Hubert D, Guilloud-Bataille M, Lenaerts C, Feingold J, Besmond $C$. The mannose binding lectin gene influences the severity of chronic liver disease in cystic fibrosis. J Med Genet 2001;38:310-1. 